\title{
The Factors Affecting on Association of Some Carboxylic Acids Effect of Solvent, Isomerism, Conjugation Process and Steric Effect
}

\section{A.S.P. Azzouz and M.M.H. Al-Niemi}

Chemistry Department, College of Education, Mosul University

Received

Accepted

13/02/2007

04/04/2007

\section{الملغص}

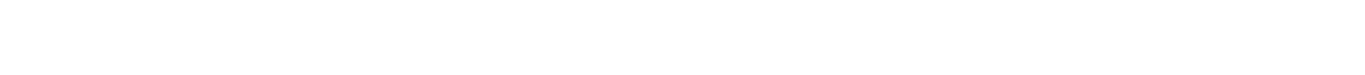

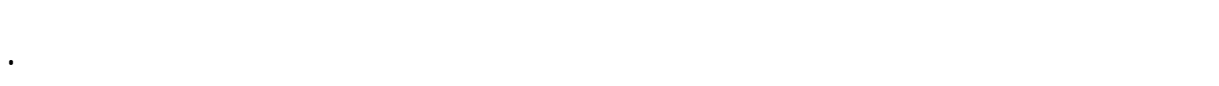

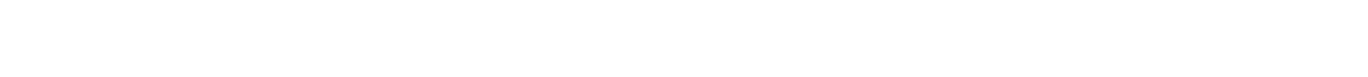

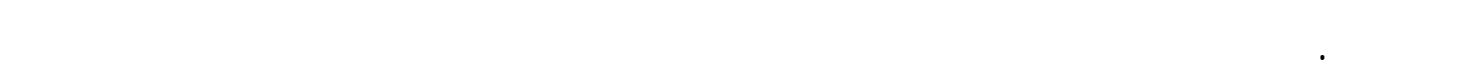

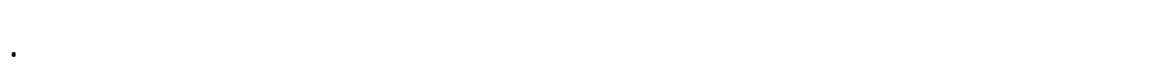

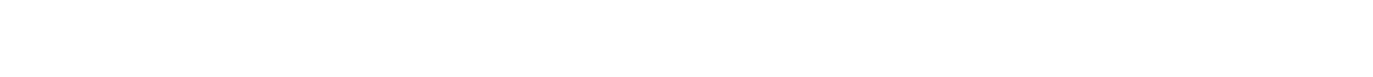

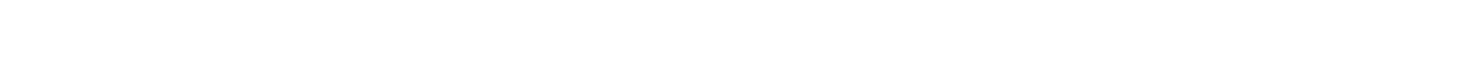

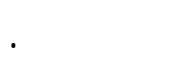

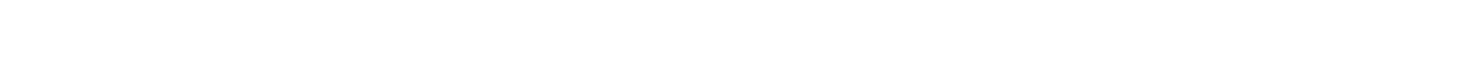
التكل بسب أن الاخير يكون المونومرات فتط .

\section{Abstract}

The study is mainly concerned with the physical factors affecting on association of carboxylic acids such as type of solvent, isomers, conjugation and steric effect of acid.

The degree of association of carboxylic acid is depend on the type of cis or trans isomer of acid. It is also increased by either increasing the number of conjugated double bonds or by introducing a polar group, taking into consideration a planer structure of acid.

Cis isomers of carboxylic acids prevent the association process by formation of acid monomers, while trans isomers facilitate the formation of dimers or polymers.

Finally exchange of solvent from non polar (benzene) to polar (nitrobenzene), prevents the association process by formation of monomers.

\section{Introduction}

In the last four decades, several works ${ }^{1-5}$ had been published in the field of association reactions. This is due to the increase of stability ${ }^{6}$ of many systems, change in absorption spectra ${ }^{5,7,8}$, and other physiochemical properties $^{6}$. 
It is well known that carboxylic acids such as acetic and formic acids can under go association ${ }^{6,9}$. The last one encourage us to deal with the factors affecting on association ${ }^{11}$ of some aliphatic and aromatic acids, namely the temperature and the structure of acids. In the last paper, it is confirmed that the association for the acids mentioned is happened not only by hydrogen bonding as stated before, but another method of association is added here and for the first time by dipole-dipole ${ }^{10}$ interaction. The study is supported by the evaluation of thermodynamic parameters, namely $\Delta \mathrm{G}, \Delta \mathrm{H}$ and $\Delta \mathrm{S}$. Finally, the study led to the dependence of thermodynamic parameters calculated on the structures of carboxylic acids.

The lack of informations about other factors affecting on association of some carboxylic acids as type of solvent, type of isomer of acid, conjugation and steric effects in acids has prompted this work.

\section{Experimental}

Detailed of the chemicals used throughout this work, the synthesis of carboxylic acids, the evaluation of equilibrium constants by distribution method for the conversion of dimer or trimer of acid to the corresponding monomers i.e $\mathrm{K}_{2}$ and $\mathrm{K}_{3}$ respectively are shown in our previous communication ${ }^{11}$. The following equations are used graphically by using a computer programme in the evaluation of equilibrium constants $K_{2}$ and $K_{3}$. Also $K_{1}$ is the value of distribution coefficient, $C_{0}$ and $\mathrm{C}_{\mathrm{w}}$ are concentration of solute in organic (benzene), and water phases respectively.

$$
\begin{aligned}
& \mathrm{C}_{\mathrm{o}} / \mathrm{C}_{\mathrm{w}}=\mathrm{K}_{1}+\frac{2 \mathrm{~K}_{1}^{2}}{\mathrm{~K}_{2}} \cdot \mathrm{C}_{\mathrm{w}} \ldots \ldots \text { (1) } \\
& \mathrm{C}_{\mathrm{o}} / \mathrm{C}_{\mathrm{w}}=\mathrm{K}_{1}+\frac{{ }^{3} \mathrm{~K}_{1}^{3}}{\mathrm{~K}_{3}} \cdot \mathrm{C}_{\mathrm{w}}^{2} \ldots \ldots \text { (2) }
\end{aligned}
$$

The degree of association of any carboxylic acid is evaluated simply from equation (3) of the form

$$
\log \mathrm{C}_{\mathrm{w}}=\text { constant }+1 / \mathrm{n} \log \mathrm{C}_{\mathrm{o}}
$$

Here are the nomenclature and the abbreviation of acids used throughout the work.

4-Nitrobenzoic acid (4-NBA), 2-nitrobenzoic acid (2-NBA), 2flurobenzoic acid (2-FBA), 3-flurobenzoic acid (3-FBA), 4-flurobenzoic acid (4-FBA), 3-methoxybenzoic acid (3-MBA), 2-methoxybenzoic acid (2-MBA), 4-methoxybenzoic (4-MBA), 2-hydroxybenzoic acid (2-HBA), 4-carboxybenzoic acid (4-CBA), trans-cinnamic acid (TCA), maleic acid 
(MA) and fumaric acid (FA). These acids are mostly prepared by standard method ${ }^{11}$.

\section{Instrumentation:}

1. The $\mathrm{pH}$ or potential of any solution has been measured by using Philips PW $9421 \mathrm{pH}$ meter.

2. A Searle thermostat of model L200 is used to maintain a fixed temperature.

\section{Results and Discussion}

\section{Effect of solvent on association:}

The solvent has a great influence on many equilibrium reactions ${ }^{12}$, as dissociation of acids or bases, Keto-enol equilibria and others ${ }^{13}$. All these studies encourage the workers to study the influence of solvent on the equilibrium reaction of dimer $\rightleftharpoons \mathrm{n}$ monomer of acid. The study includes 4-FBA and 4-MBA as a representative examples and in polar and nonpolar solvents as in Table(1), which summarizes the following points :

a. The degrees of association (n) of 4-FBA and 4-MBA at a range of temperature (283-303) $\mathrm{K}$ and in benzene and nitrobenzene are about two and one respectively. This is because nitrobenzene as a polar solvent, inhibit the association process. This comes in agreement ${ }^{14}$ with the association studies on Schiff bases derived from 2,3dihydroxybenzaldehyde and substituted aniline. Benzene solvent facilitate the association of any two monomers of acid by intermolecular forces cited above.

b. In nitrobenzene solvent, since the degree of association of the acids mentioned is one. This led to the difficult evaluation of equilibrium constant value $\mathrm{K}_{2}$ in such solvent.

\section{Effect of isomerism on association:}

The process of isomerisation can be performed experimentally by thermal $^{15}$, photochemical ${ }^{16}$ and catalytic ${ }^{17}$ methods. In 1982 Saleem $^{18}$ had applied the lanthanide Schiff reagent in the trans-cis isomerisation of $\mathrm{N}$ benzylidene anilines.

In this study, the effect of isomerism on the dissociation reaction in acids become obvious. It is applied to cis and trans geometrical acid isomers as MA and FA respectively. These acids are found to contain intra and intermolecular a hydrogen bonding respectively. The last agrees $^{9}$ with earlier report. Tables (2-3) show the following:

a. The degree of association of MA at $283 \mathrm{~K}$ is about unity. This means that the association process in such acid is difficult, due to the intramolecular ${ }^{9}$ hydrogen bonding. Hence, it is difficult to evaluate the equilibrium constant $\mathrm{K}_{2}$ of reaction mentioned before. 
b. The degrees of association of FA at a range of temperatures (283-303) $\mathrm{K}$ have an approximate values in a range 1.23-2.02. The reason for such variation is due to fact that the association process in such acid is occurred by intermolecular hydrogen bonding. The existence of hydrogen bond in FA is confirmed by its weakening ${ }^{4,5}$ upon elevation of temperature. Finally these results are supported with a similar study $^{11}$ on TCA which have an association degree values in a range two to near four as shown in Table (3).

\section{Effect of conjugation on association:}

In the first instance a broad aspects of conjugation process and its relationship with association process, may led to an uncouraging and misleading connection. Actually the conjugation may facilitate the motion of $\pi$-electrons from rich electronic center to poor ones. This produces a polarization of any molecule or a formation of dipoles, taking into consideration a planer structure of molecule, as shown in the following resonance structures of conjugated acid:<smiles>[R]C=CC(=O)O</smiles>

Hence, it can be concluded that conjugation process and to certain extent is responsible on formation of dipoles in any organic acid. This agrees with the fact that organic acids under study associates with dipoledipole interactions ${ }^{10}$ in addition to hydrogen bonding as mentioned before.

By comparison of degrees of association of benzoic acid, TCA and 4-CBA in benzene give an experimental value ${ }^{6-9}$ of two to the first acid and a range of values 2.2-3.6 and 1.79-3.2 to the other acids respectively as in Table (3). The number of double bonds in benzoic acid and TCA are three and four respectively. This shows that increasing the double bond is accompanied by increasing the degree of association by dipole-dipole interactions ${ }^{11}$. This illustrates the influence of conjugation in acid on the ability of association.

Now 4-CBA and TCA acids have the same numbers of double bonds. So comparison of their degrees of association is thought to be essential and of great importance. Here it is anticipated that the degree of association of 4-CBA is greater than TCA. This is because that the first acid contains a two polar carboxylic groups. Experimentally, the reverse of such result is true. The only possible answer to such case is by assuming that 4 -CBA has a nonplanar ${ }^{19}$ structure. The last proposal reduces the polarization of acid and decreases the intermolecular forces between any two adjacent molecules of acid. Finally, it is believed that both the polar carboxylic group and the conjugated double bonds may contribute in association of acids mentioned. 


\section{Effect of steric on association:}

During the last decades steric effect had been applied successfully for a number of interesting reaction, namely the dissociation constants ${ }^{20}$ of benzaldoximes, the tautomerism ${ }^{21}$ of some carbonyl systems and the kinetic $^{22}$ study of benzaldoximes. Wall ${ }^{23}$ and Banes had observed that steric effect by methyl groups in ortho and meta position in benzoic acid led to the evaluation of different equilibrium constants values. Hence this paper adds other groups in ortho position and in the benzoic acid nucleus. Actually, the influence of steric effect on association process in acids and in benzene solvent can be understood from the value of degree of association (n) at 283K estimated . Hence, in this study acids , 2-HBA, 2-NBA and 2-FBA have $n$ values of $0.80,0.70$ and 0.83 respectively , or they have an approximate value near to one. This is due to the existence of intramolecular ${ }^{20-22}$ hydrogen bonding and steric effect in these acids, which prevent the association precess. Similarly, MA acid contains two carboxylic groups on the same ethylenic double bond. These carboxylic groups may exert some steric interaction between them. Hence it is not surprising to obtain non associates MA or has a degree of association value to 1.16 at $283 \mathrm{~K}$.

\section{Conclusion}

The study is mainly concerned with some factors affecting on association of carboxylic acids in benzene. This includes a four physical factors as:

1. Exchange of nonpolar benzene solvent by polar nitrobenzene inhibit the association of acid. This may be due to solute-solvent interaction which prevents the acid association.

2. The cis-trans isomerism has a clear influence on the degree of association (n) of maleic and fumaric acids respectively. The study indicates that cis isomer inhibit the association process i.e. $\mathrm{n}=1$ or a monomeric existence of maleic acid molecules in benzene, whereas, the trans isomer enhance the association process $n \geq 2$ or a dimeric, trimeric existence of fumaric acid and trans-cinnamic acids is observed respectively in the same solvent.

3. Increasing the conjugation or the number of double bond in acid, or introduction of polar group resulted in increasing the degree of association of an acid, taking into consideration a planer structure of acid.

4. Finally, steric effect as influenced by the introduction of ortho substituents also inhibit the association of acid molecule. This is cleared in acids 2-FBA, 2-NBA and 2-HBA which are observed in monomeric states and in benzene. 
Table (1): Effect of solvent on the conversion of dimer to monomer for 4FBA and 4-MBA at different temperatures

\begin{tabular}{|c|c|c|c|c|}
\hline Acid & Solvent & $\begin{array}{l}\text { Temp. } \\
(\mathrm{K})\end{array}$ & $\begin{array}{c}\text { Degree of } \\
\text { association (n) }\end{array}$ & $\begin{array}{l}\text { Equilibrium constant } \\
\mathrm{K}_{2} \times 10^{6}\end{array}$ \\
\hline \multirow{5}{*}{ 4-FBA } & \multirow{4}{*}{ Benzene } & 283 & 2.096 & 3.407 \\
\hline & & 288 & 1.970 & 5.976 \\
\hline & & 293 & 1.741 & 157.814 \\
\hline & & 303 & 1.624 & 371.963 \\
\hline & Nitrobenzene & 283 & 0.825 & - \\
\hline \multirow{6}{*}{ 4-MBA } & \multirow{5}{*}{ Benzene } & 283 & 1.953 & 8.058 \\
\hline & & 288 & 1.809 & 25.169 \\
\hline & & 293 & 2.243 & 48.959 \\
\hline & & 298 & 1.656 & 211.713 \\
\hline & & 303 & 1.610 & 471.722 \\
\hline & Nitrobenzene & 283 & 1.065 & - \\
\hline
\end{tabular}

Table (2): Results of non-associated carboxylic acids in benzene at $283 \mathrm{~K}$

\begin{tabular}{|c|c|c|c|c|c|}
\hline Symbol & Intercept & Slope & $\begin{array}{c}\text { Degree of } \\
\text { association (n) }\end{array}$ & $\begin{array}{c}\text { Correlation } \\
\text { coefficient }\end{array}$ & $\begin{array}{c}\text { Standard } \\
\text { error }\end{array}$ \\
\hline 2-NBA & 1.4828 & 1.43958 & 0.695 & 0.979118 & 0.017598 \\
\hline 2-FBA & 0.688716 & 1.21247 & 0.825 & 0.999188 & 0.010515 \\
\hline 2-HBA & 0.8359 & 1.24674 & 0.802 & 0.999795 & 0.003225 \\
\hline MA & -0.813514 & 0.866024 & 1.155 & 0.953551 & 0.014598 \\
\hline
\end{tabular}

Table (3): Results of associated carboxylic acids in benzene at various temperature

\begin{tabular}{|c|c|c|c|c|c|c|}
\hline Symbol & $\begin{array}{c}\text { Temperature } \\
(\mathrm{K})\end{array}$ & Intercept & Slope & $\begin{array}{c}\text { Degree of } \\
\text { association (n) }\end{array}$ & $\begin{array}{c}\text { Correlation } \\
\text { coefficient }\end{array}$ & $\begin{array}{c}\text { Standard } \\
\text { error }\end{array}$ \\
\hline \multirow{4}{*}{ 4-CBA } & 283 & -1.89531 & 0.557391 & 1.794 & 0.996124 & 0.006290 \\
\cline { 2 - 7 } & 288 & -2.32992 & 0.38013 & 2.631 & 0.993397 & 0.064437 \\
\cline { 2 - 7 } & 293 & -2.56435 & 0.36006 & 2.777 & 0.971855 & 0.90922 \\
\cline { 2 - 7 } & 298 & -2.51124 & 0.321223 & 3.113 & 0.982984 & 0.009409 \\
\cline { 2 - 7 } TCA & 303 & -2.52542 & 0.304973 & 3.279 & 0.996922 & 0.003136 \\
\hline \multirow{4}{*}{ FA } & 283 & -2.16114 & 0.447874 & 2.233 & 0.992411 & 0.011897 \\
\cline { 2 - 7 } & 288 & -2.14677 & 0.384379 & 2.602 & 0.997984 & 0.006933 \\
\cline { 2 - 7 } & 293 & -2.37287 & 0.341282 & 2.930 & 0.998710 & 0.004981 \\
\cline { 2 - 7 } & 298 & -2.58208 & 0.310348 & 3.222 & 0.994233 & 0.008873 \\
\hline & 303 & -2.44037 & 0.277537 & 3.603 & 0.997767 & 0.002696 \\
\cline { 2 - 7 } & 283 & -2.05442 & 0.495854 & 2.017 & 0.99762 & 0.003380 \\
\cline { 2 - 7 } & 298 & -2.01674 & 0.512376 & 1.952 & 0.995518 & 0.005689 \\
\cline { 2 - 7 } & 298 & -2.04246 & 0.516232 & 1.937 & 0.992933 & 0.006135 \\
\hline & 303 & -1.43832 & 0.683637 & 1.463 & 0.996091 & 0.005766 \\
\hline
\end{tabular}




\section{References}

1. G.C. Pimentel and A.L. McClellan, "The Hydrogen Bond", W.H. Freeman, San Francisco, (1960).

2. J. Favrot, J.M. Leclereq, R. Roberge, C. Sandorfy and D. Vocelle, Photochem. Photobiol., 29(1979)99.

3. M. Bissonett, H. Lethanh and D. Vocelle, Can. J. Chem., 62 (1984) 1459.

4. S.K. Al-Dilami, A.S.P. Azzouz and N.G. Ahmad, Muta J. Res. and Stud., 7(1992)407.

5. A.S.P. Azzouz, Z. Phys. Chem., 216(2002)1.

6. A. Martin, Physical Pharmacy, 4th ed., Lean and Febiger, (1993), pp. 408-494.

7. S.K. Al-Dilami, J.C. Aumiller, R.H. Johnson and P.E. Blatz, Photochem. Photobiol., 46(1987)403.

8. A.S.P. Azzouz, A.A.S. Siddieq and E.Z. Sulyman, J. Edu. Sci., 51(2001)83.

9. R. Chang, "Physical Chemistry with Applications to Biological Systems", Macmillan, New York, (1981), p. 487-501.

10. M. Ladd, "Introduction to Physical Chemistry", 3rd ed., Cambridge, (1998), p. 217-221.

11. A.S.P. Azzouz and M.M. Al-Niami, Cited for publication.

12. C. Reichardt, Solvents and Solvent Effects in Organic Chemistry, (1988) VCH Publisher, Germany.

13. U. Mayer, Ionic equilibrium in donor solvents, Pure Appl. Chem., 41(1975)291.

14. A.S.P. Azzouz and S.M. Saleh, J. Edu. Sci., 46(2000)51.

15. J.W. Le Favre and J. Nortchoolt, J. Chem. Soc., (1949) 2235.

16. G.M. Wyman, Chem. Rev., 55(1955)625.

17. M.J. Copley and C.E. Holley, J. Am. Chem. Soc., 61(1939)1599.

18. L.M.N. Saleem, Org. Mag. Res., 19(1982)176.

19. P. Sykes, A Guide Book to Mechanism in Organic Chemistry, (1963), 5th ed., London.

20. A.S.P. Azzouz and S.S. Othman, J. Educ. Sci., 26(1997)26.

21. A.S.P. Azzouz, Mutah J. Res. and Stud., 8(1993)93.

22. S.K. Al-Dilami, A.S.P. Azzouz and B.D. Kishmola, Iraqi J. Chem., 15(1990)288.

23. I.T. Wall and F.W. Banes, J. Am. Chem. Soc., 67(1945)808. 